\section{PS-165 DOES GENERAL ANAESTHESIA EXPOSURE EFFECT ADVERSE NEURODEVELOPMENTAL OUTCOᄀMES IN VERY PRETERM INFANTS?}

E Calisici, Z Eras, MY Oncel, H Degirmencioglu, FE Canpolat, SS Oguz, U Dilmen. Neonatology, Zekai Tahir Burak Maternity Teaching Hospital, Ankara, Turkey

\subsection{6/archdischild-2014-307384.461}

Background and aims General anaesthetics may produce neurotoxicity and enduring cognitive impairment in animal models, but the issue has not been adequately studied in humans. We want to demonstrate the association of poor neurodevelopmental outcome in preterm neonates who underwent anaesthesia during their neonatal period.

Methods Total of 120 infants in infants born very preterm ( $\leq$ 32 weeks) with very low birthweight $(<1500 \mathrm{~g})$ were enrolled in a retros-pective randomised controlled trial classed into two groups. Group $1(n=60)$ underwent general anaesthesia for any surgical state on follow-up and group $2(n=60)$ was no given anaesthesia. Both of groups were compared in terms of clinical demographic data. Cognitive and neu-romotor development were assessed by using the Bayley Scales of Infant Development II.

Results No statistical difference between demographic data. The mental developmental index (MDI) and physical developmental in-dex scores were $76.73 \pm 23.88 ; 76.26 \pm 20.22$ in group 1 and $96.6 \pm 12.87 ; 89.1 \pm 16.75$ in group 2 , respectively. There was significant difference in growth and neurodevelopmental outcomes between the two groups (MDI: $\mathrm{p}=0.001$; PDI: $\mathrm{p}=$ 0.01). There was no in-dependent risk factor, which can affect none of the MDI and PDI scores in the multinomial logistic regression analysis.

Conclusion One of the most important problem of prematurity is poor neurodevelopmental outcome. Sedatives and anaesthetics which widely used in animal studies, showed widespread structural damage after exposure to the newborn period and lasting neuro-cognitive abnormalities in brain development. Anaesthetics exposure in preterm infants among surgery is an independent increased risk factor for poor neurodevelopment.

\section{PS-166 NEURODEVELOPMENT OUTCOME DURING TODDLERHOOD IN VERY LOW BIRTH WEIGHT INFANTS WITH ABSENT OR REVERSE END DIASTOLIC FLOW IN THE UMBILICAL ARTERY DURING PREGNANCY}

${ }^{1} \mathrm{~S}$ Brütsch, 'T Burkhardt, ${ }^{1} \mathrm{~J}$ Kurmanavicius, ${ }^{1} \mathrm{R}$ Zimmermann, ${ }^{1} \mathrm{~N}$ Ochsenbein-Kölble, ${ }^{2} \mathrm{G}$ Natalucci. 'Obstetrics, University Hospital of Zurich, Zurich, Switzerland; ${ }^{2}$ Neonatology, University Hospital of Zurich, Zurich, Switzerland

\subsection{6/archdischild-2014-307384.462}

Background and aim Antenatal absent or reverse end-diastolic flow (AREDF) in the umbilical artery (UA) is associated with high perinatal morbidity and mortality. We aimed to assess the neurodevelopment outcome during toddlerhood of very low birth weight preterm infants with AREDF in the UA during pregnancy.

Methods We compared longitudinally collected neurodevelopment outcome data of surviving preterm infants born in our institution in 1996-2010 with birth weight $<1500 \mathrm{~g}$ and with AREDF in the UA with those of sex-, gestational age-, birth weight-, and birth year-matched infants with prenatal normal UA-Doppler parameters. Neurodevelopment outcome was evaluated at a mean (SD) corrected age of 20.6(8.1) months by the BSID-II and neurological examination.

Results Forty-one infants for both groups were recruited. Neonatal and socio-demographic characteristics of both groups were similar except for the confounders caesarean section, antenatal corticosteroids (higher in AREDF group, $p=0.01$ and 0.02, respectively), and mother's age (lower in AREDF group, $\mathrm{p}=$ 0.01). Mean (SD) mental development index of children with AREDF in the UA $(81.8,16.3)$ was significantly lower $(\mathrm{p}=$ 0.02) compared to controls $(92.4,16.3)$. This result remains significant after adjustment for confounders. No significant differences in the psychomotor development index or in the distribution of cerebral palsy were observed between the two groups.

Conclusion Preterm infants with abnormal antenatal Doppler in the UA have a higher risk for adverse neurodevelopment outcome during toddlerhood compared to sex-, gestational age-, birth weight-, and birth year-matched controls. AREDF in the UA might be considered a prenatal predictor of adverse neurodevelopment outcome in this population.

\section{PS-167 WITHDRAWN \\ PS-168 LONG-TERM RENAL COMPLICATIONS IN THE REGIONAL COHORT OF ELBW CHILDREN: CORRELATION BETWEEN RESULTS AQUIRED AT THE AGE OF 7 AND AGE OF 11 YEARS}

${ }^{1} \mathrm{P}$ Kwinta, ${ }^{1} \mathrm{M}$ Klimek, ${ }^{1} \mathrm{M}$ Jagla, ${ }^{1} \mathrm{~A}$ Grudzien, ${ }^{2} \mathrm{D}$ Drozdz, ${ }^{1} \mathrm{~K}$ Starzec, ${ }^{1} \mathrm{JJ}$ Pietrzyk. ${ }^{1}$ Department of Pediatrics, Jagiellonian University, Krakow, Poland; ${ }^{2}$ Department of Pediatric Nephrology, Jagiellonian University, Krakow, Poland

\subsection{6/archdischild-2014-307384.463}

Aim Assessment of renal long-term complications in the regional cohort of ELBW children born in 2002-2003.

Methods 40 children (17 born as ELBW infants and 23 fullterm control children randomly selected from one GP office) were assessed at the age of 7 years and next prospectively observed up to 11 years. Serum creatinine, Cystatin C, renal ultrasound and 24-hours ambulatory blood pressure measurements (ABPM) were performed.

Results Mean birthweight of the ELBW group equaled $825 \mathrm{~g}$, and mean gestational age equaled 26.5 weeks. Mean renal volume at the age of 7 years was: ELBW group - left kidney (LK) $37 \mathrm{ml}$; right kidney (RK) 40ml, control group - LK 59ml; RK $60 \mathrm{ml}$ ( $\mathrm{p}<0.01$ for both kidneys). The increase of renal volume between the age of 7 and 11 was similar in both groups. The volume of kidneys at the age of 11 years was: ELBW group - LK $51 \mathrm{ml}$; RK $56 \mathrm{ml}$, control group - LK $67 \mathrm{ml}$; RK $70 \mathrm{ml}$ ( $\mathrm{p}<0.01$ for both kidneys). Calculated eGFR values at the age of 7 and 11 years were similar in both groups (ELBV group at the age of 7 and 11 respectively: 124 vs. 123 ; control group 127 vs. 114 $\left.\mathrm{ml} / \mathrm{min}^{*} 1,72 \mathrm{~m}^{2}\right)$. The mean arterial blood pressure (ABPM) increased significantly between both time points (ELBW group: 79 vs. 83 , control group: 77 vs. $81 \mathrm{mmHg}$ ).

Conclusions The smaller renal volume observed in the assessed ELBW children at the age of 7 years persisted up to the age of 11 years, however the renal function seems to be intact. 